\title{
Evaluation of portal blood flow using transcutaneous and intraoperative Doppler ultrasonography in dairy cows with fatty liver
}

\author{
A. Starke, ${ }^{\star 1,2}$ S. Schmidt, ${ }^{\star 1}$ A. Haudum, ${ }^{* 1}$ T. Scholbach,, P. Wohlsein, $\ddagger$ M. Beyerbach,§ and J. Rehage* \\ ${ }^{*}$ Clinic for Cattle, University of Veterinary Medicine, 30173 Hannover, Germany \\ †Hospital for Children and Adolescents, 09116 Chemnitz, Germany \\ ‡Department of Pathology, and \\ §Institute for Biometry, Epidemiology and Information Processing, University of Veterinary Medicine, 30173 Hannover, Germany
}

\begin{abstract}
The objective of the study was to investigate portal blood flow $(\mathrm{PBF})$ in dairy cows with fatty liver by means of Doppler ultrasonography. Eighty lactating German Holstein cows less than 100 d in milk were used (mean \pm standard error of the mean; body weight: 583 $\pm 9 \mathrm{~kg}$, age: $5 \pm 0.2 \mathrm{yr}$, withers height: $145.4 \pm 0.5 \mathrm{~cm}$, milk yield: $9 \pm 0.6 \mathrm{~kg}$ ). All cows had left abomasal displacement and underwent omentopexy via right flank laparotomy. The size of the liver and the thickness over the portal vein were determined ultrasonographically. Doppler ultrasonographic examinations of PBF were carried out transcutaneously and intraoperatively directly via liver surface. The PBF velocities [peak maximum $\left(\mathrm{v}_{\max }\right)$, peak minimum $\left(\mathrm{v}_{\min }\right)$, and mean maximum $\left(\mathrm{v}_{\text {mean }}\right)$ velocity] were recorded. Venous pulsatility index (VPI) was calculated. Because transcutaneous Doppler ultrasonography revealed images of very poor quality in 58 of the 80 cows, only data obtained intraoperatively were presented. Liver biopsies were used for hepatic triacylglycerol (TAG) determination and histological examination. Based on histopathologic and ultrasonographic examinations, none of the cows suffered from hepatic disorders other than hepatic lipidosis. Hepatic TAG content ranged from 5 to $292 \mathrm{mg} / \mathrm{g}$ of liver fresh weight (FW). Cows were allocated to 1 of 4 groups according to their hepatic TAG content (very severe: TAG $>150 \mathrm{mg} / \mathrm{g}$ of $\mathrm{FW}, \mathrm{n}=27$; severe: $>100-150$ $\mathrm{mg} / \mathrm{g}$ of $\mathrm{FW}, \mathrm{n}=18$; moderate: $\geq 50-100 \mathrm{mg} / \mathrm{g}$ of $\mathrm{FW}$, $\mathrm{n}=19$; mild: $<50 \mathrm{mg} / \mathrm{g}$ of $\mathrm{FW}, \mathrm{n}=16$ ). The VPI decreased with increasing TAG content $(\mathrm{r}=-0.55)$. The VPI did not differ between cows with severe and very severe fatty liver but it differed between cows of these 2 groups and cows with mild and moderate fatty liver. Velocities of PBF ( $\mathrm{v}_{\text {mean }}, \mathrm{v}_{\min }, \mathrm{v}_{\max }$ ) correlated negatively with hepatic TAG content $(\mathrm{r}=-0.26$ to -0.37$)$.
\end{abstract}

Received January 8, 2011.

Accepted February 18, 2011.

${ }^{1}$ These authors contributed equally.

${ }^{2}$ Corresponding author: alexander.starke@tiho-hannover.de
Mean PBF velocity of the cows with very severe fatty liver differed from cows with severe, moderate, and mild fatty liver. Variables of PBF were inversely related to hepatic size and thickness $(\mathrm{r}=-0.06$ to -0.35$)$. In conclusion, the lower VPI and PBF velocities in cows with fatty liver and the negative correlations with the degree of hepatosteatosis may be explained by a reduction of vascular compliance in the liver because of fatty infiltration. These changes, which are believed to result from parenchymal swelling, were particularly pronounced when hepatic TAG content exceeded 150 $\mathrm{mg} / \mathrm{g} \mathrm{FW}$.

Key words: fatty liver, portal and hepatic blood flow, intraoperative Doppler ultrasonography, triacylglycerol

\section{INTRODUCTION}

Approximately 40 to $60 \%$ of high-producing dairy cows develop moderate to severe fatty liver during early lactation (Jorritsma et al., 2000, 2001; Raoofi et al., 2001). In hepatic lipidosis, the accumulated fat consists mainly of triacylglycerol (TAG) and is evenly distributed throughout the organ (Gröhn and Lindberg, 1982; Gaál and Husveth, 1983). Accumulation of fat in hepatocytes causes parenchymal swelling and thereby an increase in hepatic volume and size (Reid and Collins, 1980; Johannsen et al., 1993). The shape and contour of the liver change and the margins become round during episodes of fatty liver (Morrow et al., 1979; Maxie, 2007; Haudum et al., 2011). These changes indicate that the tight fibrous capsule of the liver (Liebich, 1999) has only limited potential for expansion (Kremer et al., 1993; McGavin and Zachary, 2007; Braun, 2009). In rodents and humans with fatty liver, parenchymal swelling leads to an increase in hepatic pressure and compression of hepatic blood vessels (Orrego et al., 1981). This may result in abnormal hepatic microcirculation, reduction in portal and total hepatic blood flow, and increased portal venous pressure (Seifalian et al., 2001; Magalotti et al., 2004; McCuskey et al., 2004), or even hepatic local ischemia (Sun et al., 2003). In dairy cows, compression of hepatic blood vessels was 
detected ultrasonographically during episodes of fatty liver (Iwao, 1987; Braun, 1990; Weijers et al., 2010). However, to the best of our knowledge no studies have elucidated the relationships of hepatic fat content and hepatic shape with portal blood flow (PBF).

Unimpaired perfusion is a prerequisite for optimal liver function (Reynolds et al., 1994, 2003), which is essential for the health and performance of high-producing dairy cows (Drackley, 1999). Because disturbed perfusion (Seifalian et al., 2001) may impair liver function during episodes of fatty liver in dairy cows (Drackley, 1999; Bobe et al., 2004), the objective of this study was to investigate $\mathrm{PBF}$ in dairy cows with fatty liver using Doppler ultrasonography.

\section{MATERIALS AND METHODS}

The study was conducted under the guidelines of the Research Animal Act (research permit number 33.42502/06A372) of the Lower Saxony Federal State Office for Consumer Protection and Food Safety, Oldenburg, Germany.

\section{Animals and Study Design}

Eighty lactating German Holstein cows less than 100 DIM were used (mean \pm SEM; BW: $583 \pm 9 \mathrm{~kg}$, age: $5 \pm 0.2 \mathrm{yr}$, withers height: $145.4 \pm 0.5 \mathrm{~cm}$, milk yield: $9 \pm 0.6 \mathrm{~kg}$ ). All cows had left abomasal displacement (LDA), and were referred to the authors' clinic for surgical correction by right flank laparotomy and omentopexy (Dirksen, 1967).

All cows underwent a thorough clinical examination (Stöber, 1990) to rule out diseases other than LDA, particularly inflammatory diseases such as mastitis, metritis, or endometritis. Animals were weighed on a livestock scale, and the withers height was measured (cattle measuring stick, Hauptner \& Herberholz GmbH \& Co. KG, Solingen, Germany). Backfat thickness (BFT) was measured ultrasonographically. The liver was examined via transcutaneous and intraoperative ultrasonography, and liver biopsy samples for hepatic TAG measurement were obtained during laparotomy.

\section{Ultrasonographic Examination}

Transcutaneous ultrasound examination (Power Vision 6000, Toshiba Inc., Tokyo, Japan) was carried out before surgery in nonsedated, standing animals according to Braun (1990, 2009). The skin of the right abdominal wall between the 7 th and 12th intercostal space (ICS) from the region of the longissimus dorsi muscle to the elbow joint was shaved, washed, and defatted with $70 \%$ alcohol. Ultrasound contact gel (Waldeck
GmbH and Co. KG, Muenster, Germany) was applied to the costal part of the abdominal wall. First, the liver was examined using brightness (B)-mode for the presence of morphologic changes, such as abscess, tumor, or vascular thrombosis (Braun et al., 1996). Thereafter, the size of the liver and the thickness over the portal vein were measured ultrasonographically in the 10th and 11th ICS, as described by Haudum et al. (2011).

Transcutaneous Doppler ultrasonographic examination of PBF was carried out in the pulsed wave (PW)mode from the 10th or 11th ICS on the right in the area of the hepatic portal immediately before the portal vein divides into the right and left portal branches. Five ultrasonographic images of recorded Doppler waves were saved on a magnetic optical disc in JPEG format for further analysis. Recordings were taken during maximum inspiration and only when the angle deviation between the ultrasound beam and blood flow was less than $60^{\circ}$. Backfat thickness was measured ultrasonographically using a $6-\mathrm{MHz}$ linear transducer (image depth range of $6 \mathrm{~cm}$ ) along an imaginary line between the tuber ischiadicum and tuber coxae as described by Schröder and Staufenbiel (2006).

Abomasal displacement was corrected via right flank laparotomy and omentopexy in standing, nonsedated cows without complications. Local anesthesia was achieved using paralumbar nerve blocks and infiltration of the incision line with approximately $160 \mathrm{~mL}$ of local anesthetic (procaine hydrochloride, Procaine 2\%, Selectavet, Weyarn-Holzolling, Germany). Before surgery and on the 2 subsequent days, all cows were given flunixin meglumine $(2.2 \mathrm{mg} / \mathrm{kg}$ of BW intravenously; Finadyne RP, Essex Tierarznei, Munich, Germany). During laparotomy, Doppler ultrasonographic examinations of the liver were carried out from the facies diaphragmatica as described above (Figures 1 and 2).

\section{Analysis of Doppler Flow Characteristics}

Doppler analysis was carried out off-line on a personal computer using a computer-assisted image analyzing program (Chameleon-Software, version 06_09_04, PixelFlux Scientific, Leipzig, Germany; Honnens et al., 2008) for assessment of blood flow velocities, peak maximum velocity $\left(\mathbf{v}_{\max }\right)$, peak minimum velocity $\left(\mathbf{v}_{\min }\right)$, and mean maximum blood flow velocity $\left(\mathbf{v}_{\text {mean }}\right)$. The diameter of the portal vein was measured, its area calculated (A), and the blood flow volume (BFV) was calculated using the formula

$$
\operatorname{BFV}(\mathrm{L} / \mathrm{h})=\mathrm{v}_{\text {mean }}(\mathrm{cm} / \mathrm{s}) \times 3.6 \times \mathrm{A}\left(\mathrm{cm}^{2}\right) .
$$

Envelopes of blood flow curves that were recorded using Doppler ultrasonography were analyzed and the re- 


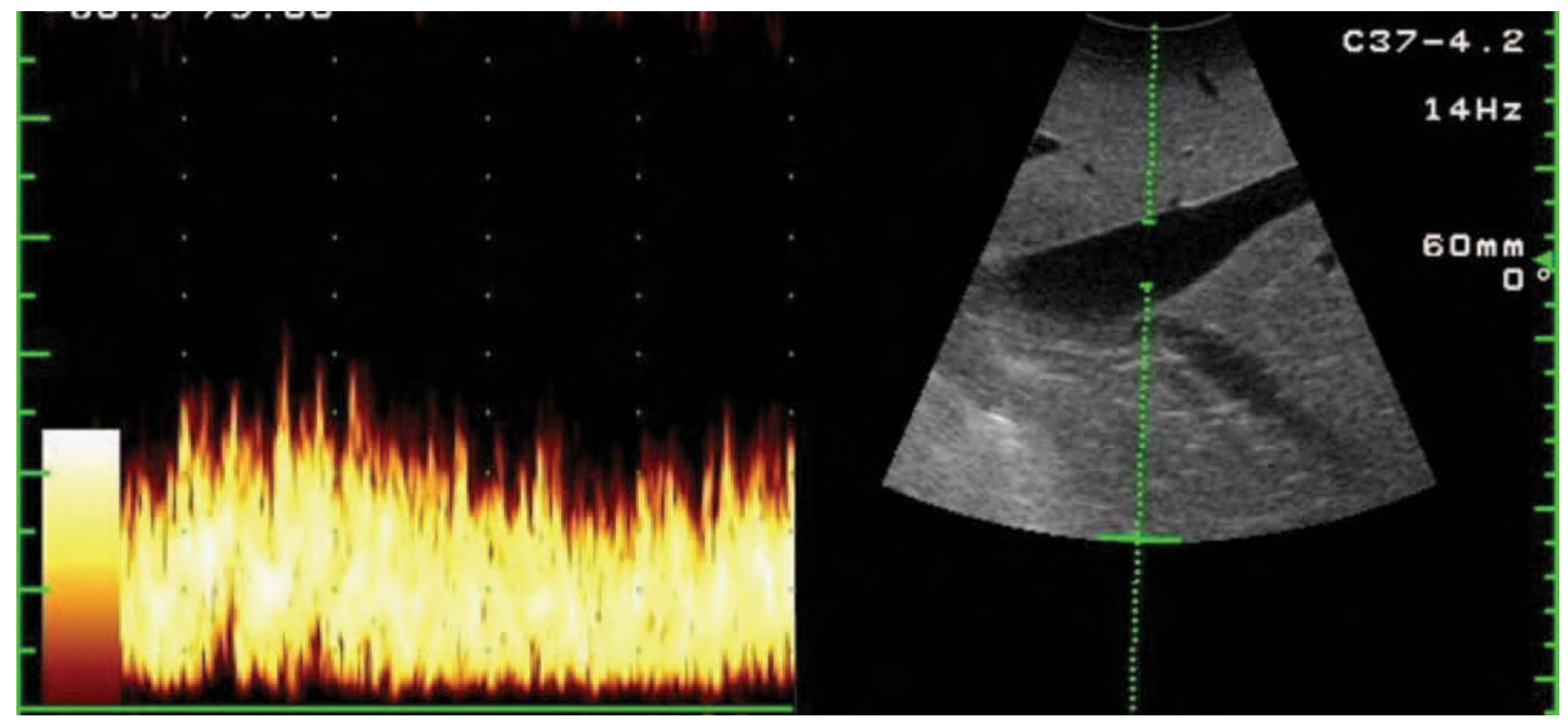

Figure 1. Intraoperative duplex Doppler examination (Power Vision 6000, Toshiba Inc., Tokyo, Japan, convex array transducer, 4.2 MHz, image size/depth range $12 \mathrm{~cm}$ ) of the portal vein of a German Holstein cow with mild hepatosteatosis. Doppler waveform shows slightly damped pulsatility with venous pulsatility index of 0.65 . Color version available in the online PDF.

sistance index $(\mathbf{R I})$, representing an angle-independent variable, was calculated automatically by the computer program. Resistance index corresponds to the venous pulsatility index (VPI) of the portal vein because for the calculation of the VPI, the same indices are used as for RI (Gallix et al., 1997). Thus, the RI values from PixelFlux measurements were also used as VPI values:

$$
\mathrm{RI}=\mathrm{VPI}=\left(\mathrm{v}_{\max }-\mathrm{v}_{\min }\right) / \mathrm{v}_{\max } .
$$

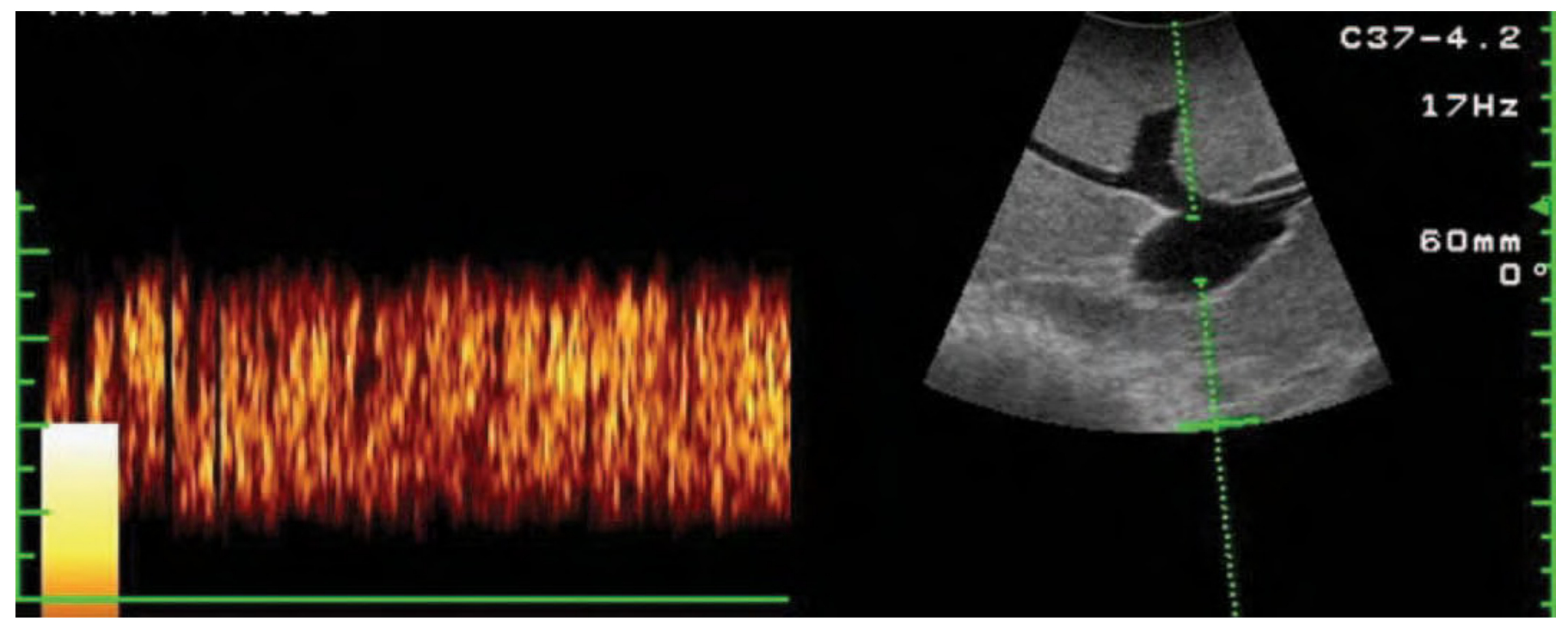

Figure 2. Intraoperative duplex Doppler examination (Power Vision 6000, Toshiba Inc., Tokyo, Japan, convex array transducer, $4.2 \mathrm{MHz}$ image size/depth range $12 \mathrm{~cm}$ ) of the portal vein of a German Holstein cow with very severe hepatosteatosis. Doppler waveform shows almost no pulsatility with venous pulsatility index of 0.07 . Color version available in the online PDF. 
For statistical evaluation, the means of results from 5 transcutaneous and 5 intraoperative ultrasonographic recordings were used.

\section{Liver Biopsy and Hepatic TAG Analysis}

Liver biopsy samples were collected during surgery, stored at $-85^{\circ} \mathrm{C}$, and analyzed biochemically for hepatic TAG content (Starke et al., 2010a), expressed as milligrams per gram of liver fresh weight $(\mathbf{F W})$ and used as a reference value for fatty liver. Liver samples were also fixed in $10 \%$ formalin, embedded in paraffin wax, sectioned, stained with hematoxylin and eosin, and examined histologically for lesions other than hepatosteatosis (Starke et al., 2010b).

\section{Statistical Analysis}

Statistical analysis was done using the SAS system for Windows (version 9.1, SAS Institute Inc., Cary, NC). For statistical analysis, cows were allocated to fat classes according to their hepatic TAG content as follows (Haudum et al., 2011): very severe: TAG > 150 $\mathrm{mg} / \mathrm{g}$ of FW; severe: $>100$ to $150 \mathrm{mg} / \mathrm{g}$ of $\mathrm{FW}$; moderate: $\geq 50$ to $100 \mathrm{mg} / \mathrm{g}$ of $\mathrm{FW}$; and mild: $<50 \mathrm{mg} / \mathrm{g}$ of FW. The Shapiro-Wilk test was adopted to test for normality of distributions of continuous variables (PROC UNIVARIATE of SAS). Pearson correlation coefficients (PROC CORR of SAS) were calculated for the relationships between patient data, ultrasonographically measured variables of the PBF, and hepatic TAG concentrations, and between ultrasonographically obtained $\mathrm{PBF}$ variables and liver size and thickness. Means of patient data were expressed as mean \pm SEM and tested for significant differences among TAG classes by means of t-distributed test statistics (PROC GLM of SAS,
LSMEANS statement, option PDIFF/TDIFF) when the global $F$-test was significant $(P<0.05)$.

A linear one-way analysis of covariance (PROC GLM of SAS) with DIM, age, and milk yield as covariates was used to evaluate the means of PBF variables for the 4 TAG classes; therefore, these means were adjusted for the effects of the 3 patient data variables. If the global $F$-test from analysis of covariance was significant $(P<$ $0.05)$, the adjusted means were also tested for significant class differences using t-distributed test statistics (PROC GLM of SAS, LSMEANS statement, option PDIFF/TDIFF).

\section{RESULTS AND DISCUSSION}

Approximately $56 \%$ of the 80 cows had severe $(>100$ to $150 \mathrm{mg}$ of $\mathrm{TAG} / \mathrm{g}$ of $\mathrm{FW})$ or very severe $(>150$ mg of TAG/g of FW) fatty liver (Table 1), similar to published prevalence rates of fatty liver in dairy cows during early lactation (Herdt, 1988; Jorritsma et al., 2000; Raoofi et al., 2001).

In 58 of 80 cows, the PBF images of the transcutaneous Doppler ultrasonographic examinations were of very poor quality and could not be used for analysis. Of the remaining 22 blood flow recordings that were good quality, 20 were from cows with mild or moderate fatty liver. The echo pattern of the normal liver is caused mainly by a series of alternating interfaces between collagen and water. With increasing fat accumulation in hepatic tissue, an increasing gray level in the ultrasonographic image becomes apparent and the liver appears subjectively "brighter" (Joseph et al., 1979). This has been explained by a gradual shift from backscattering of the signal by small hepatic vessels to a massive scattering by fat droplets. The strength of the backscattered echoes increases with an increase in

Table 1. Patient data (means \pm SEM) of 80 German Holstein cows with different hepatic triacylglycerol (TAG) contents (classification according to Haudum et al., 2011)

\begin{tabular}{|c|c|c|c|c|c|c|c|c|c|c|c|c|}
\hline Item & \multicolumn{4}{|c|}{ 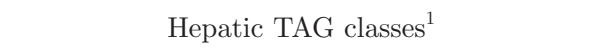 } & SEM & $\begin{array}{c}\text { Global } F- \\
\text { test }\end{array}$ & \multicolumn{6}{|c|}{$P$-value } \\
\hline \multicolumn{13}{|l|}{ Patient data } \\
\hline DIM & 15.3 & 13.7 & 16.9 & 18.8 & 3.2 & 0.75 & & & & & & \\
\hline Age (mo) & 61.8 & 66.3 & 60.5 & 47.9 & 4.6 & 0.07 & & & & & & \\
\hline Backfat thickness (mm) & 24 & 19 & 18 & 14 & 1 & $<0.001$ & 0.008 & $<0.001$ & $<0.001$ & 0.46 & 0.014 & 0.07 \\
\hline \multicolumn{13}{|l|}{ Hepatic fat content } \\
\hline $\mathrm{TAG}^{2}(\mathrm{mg} / \mathrm{g}$ of $\mathrm{FW})$ & 199.8 & 127.1 & 80.5 & 25.1 & 4.3 & & & & & & & \\
\hline
\end{tabular}


Table 2. Pearson correlation coefficients (r) of patient data, hepatic triacylglycerol (TAG) content, and portal blood flow in 80 German Holstein cows

\begin{tabular}{|c|c|c|c|c|c|c|c|c|c|c|c|c|}
\hline Item & \multicolumn{12}{|c|}{ Characteristic $^{1}$} \\
\hline $\begin{array}{l}\text { Hepatic TAG } \\
\text { Doppler flow }\end{array}$ & -0.11 & $0.26^{*}$ & $0.58^{* * *}$ & $0.21^{*}$ & 0.19 & 0.1 & 0.14 & $-0.37^{* * *}$ & $-0.26^{*}$ & $-0.33^{* *}$ & $-0.55^{* * *}$ & -0.15 \\
\hline Diameter & 0.17 & -0.08 & -0.02 & 0.02 & -0.03 & 0.14 & & $-0.36^{* *}$ & $-0.34^{* *}$ & $-0.36^{* *}$ & -0.13 & $0.63^{* * *}$ \\
\hline $\mathrm{v}_{\max }$ & -0.09 & 0.07 & -0.08 & 0.18 & 0.09 & -0.08 & & & $0.97^{* * *}$ & $0.99 * * *$ & $0.23^{*}$ & $0.47^{* * *}$ \\
\hline $\mathrm{v}_{\min }$ & -0.14 & 0.08 & -0.003 & 0.21 & 0.12 & -0.07 & & & & $0.99^{* * *}$ & -0.05 & $0.48^{* * *}$ \\
\hline $\mathrm{BFV}$ & 0.04 & 0.01 & -0.06 & 0.19 & 0.14 & -0.06 & & & & & & \\
\hline
\end{tabular}

${ }^{1} \mathrm{BFT}=$ backfat thickness; $\mathrm{WH}=$ withers height; diameter $=$ diameter of portal vein; $\mathrm{v}_{\max }=$ peak maximum blood flow velocity; $\mathrm{v}_{\min }=$ peak minimum blood flow velocity; $\mathrm{v}_{\text {mean }}=$ mean maximum blood flow velocity; VPI $=$ venous pulsatility index; BFV $=$ blood flow volume.

$* * * P<0.001 ; * * P<0.01 ; * P<0.05$.

the number of fat droplets in the liver tissue (Starke et al., 2010b). As a result, the resolution of detailed hepatic structures (e.g., the portal vein) is decreased considerably in severe fatty liver (Joseph et al., 1979; Braun, 2009; Starke et al., 2010b). Therefore, based on the results of this study, the usefulness of transcutaneous Doppler ultrasonography to monitor PBF in dairy cows with fatty liver is very limited. The number of recordings obtained by transcutaneous Doppler ultrasonography was not sufficient for a meaningful statistical evaluation. For this reason, only results gained from intraoperative Doppler ultrasonography are presented.

With increasing hepatic fat content, the pulsatility of PBF decreased (Figures 1 and 2), which was also evident from the negative correlation between VPI and TAG (Table 2). Mean VPI of cows with severe and very severe fatty liver differed from VPI of cows with mild $(P<0.001)$ or moderate $(P=0.05$ and $P<0.001$, respectively) fatty liver, but the difference between cows with severe and very severe fatty liver was not significant (Table 3 ).

Hepatic veins of healthy humans have a pulsatile triphasic or four-phasic blood flow profile (Teichgräber et al., 1997; Dietrich et al., 1998; Scheinfeld et al., 2009), which is caused by retrograde conduction of blood pressure variability from the right atrium to the caudal vena cava into the hepatic vein (Abu-Yousef et al., 1990). During atrial contraction, a brief hepatopetal blood reflux occurs (Gallix et al., 1997). The pulsatility of blood flow within the hepatic vein is principally transmitted into the portal vein, but is dampened by the elasticity of blood vessels and the hepatic tissue (Lautt et al., 1986; Greenway and Lautt, 1988). The resistance to the normal triphasic blood flow pattern increases in parallel with the increasing intrahepatic tissue pressure (Dietrich et al., 1998) that occurs in fatty liver (Orrego et al., 1981). Accordingly, pulsations of the hepatic veins decrease with increasing fat content of the organ (Gallix et al., 1997; Erdogmus et al., 2008). This is evidenced by a flattening of the portal venous pulse in humans, reflecting decreased modulation of the PBF (Dietrich et al., 1998; Erdogmus et al., 2008). According to the present study, the same occurs in dairy cows. The TAG content of the hepatocyte was the only variable associated with an independent effect on the type of flow pattern (triphasic vs. nontriphasic) in the

Table 3. Intraoperative ultrasonographically measured portal blood flow (means \pm SEM) in 80 German Holstein cows with different hepatic triacylglycerol (TAG) contents (according to Haudum et al., 2011)

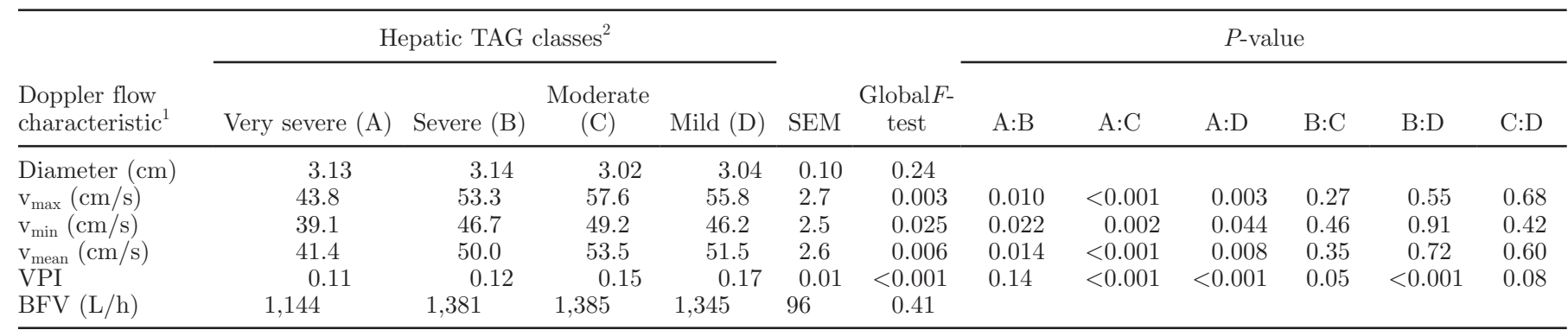

${ }^{1}$ Diameter $=$ diameter of the portal vein; $\mathrm{v}_{\max }=$ peak maximum blood flow velocity; $\mathrm{v}_{\min }=$ peak minimum blood flow velocity; $\mathrm{v}_{\text {mean }}=$ mean maximum blood flow velocity; VPI = venous pulsatility index; and BFV = blood flow volume.

${ }^{2}$ Classes: very severe $=>150(\mathrm{n}=27,34 \%$ of total $)$; severe $=>100-150(\mathrm{n}=18,22 \%) ;$ moderate $=\geq 50-100(\mathrm{n}=19,24 \%) ;$ and mild $=<50$ $(\mathrm{n}=16,20 \%) \mathrm{mg} / \mathrm{g}$ of fresh weight $(\mathrm{FW})$. 
hepatic veins (Dietrich et al., 1998). This suggested an interaction of intrahepatic phasic pressure changes in the hepatic venous outflow and the portal influx, which is disturbed in progressive hepatic fat accumulation. Our findings (Table 2) were in good agreement with the observation in humans that the VPI in the portal vein decreases with increasing liver fat (Gallix et al., 1997; Balci et al., 2008; Erdogmus et al., 2008).

Conversely, pronounced pulsation of the portal vein occurs with an increase in amplitude of the retrograde influx into the hepatic veins. This was reported in humans with tricuspid regurgitation (Abu-Yousef et al., 1990) and pericardial effusion (Görg et al., 2002). However, none of the cows in the present study had clinical evidence of heart disease, and ultrasonographic examination of the caudal vena cava (Braun et al., 2002; Mohamed et al., 2004) revealed no abnormalities. Therefore, heart diseases are an unlikely source of the variance in portal hemodynamics in the present study.

Respiratory movements lead to pressure changes within the thoracic and abdominal cavities and thus affect pulsatility and blood flow within the portal vein (Abu-Yousef, 1992). Because cows cannot be asked to temporarily hold their breath, Doppler recordings were taken only during maximal inspiration to minimize this source of variance.

Stenosis of hepatic veins can also affect hepatic hemodynamics (Bolondi et al., 1991). However, thorough transcutaneous and intraoperative ultrasonographic B-mode examination of the liver and adjacent tissues (Braun et al., 1996; Doré et al., 2007) yielded no evidence of an abscess, tumor, or thrombosis of hepatic vessels. Fibrotic and inflammatory changes of hepatic tissues, also causing substantial disturbances of hepatic blood flow, were ruled out by means of histology. Thus, the main source of variance in the pulsatility of PBF in cows of the present study appeared to be the hepatic TAG content.

Velocities of PBF ( $\mathrm{v}_{\text {mean }}, \mathrm{v}_{\min }, \mathrm{v}_{\max }$ ) revealed weak negative correlations with hepatic TAG content (Table 2 ), which was in agreement with earlier studies in humans (Balci et al., 2008; Erdogmus et al., 2008). Significant differences in PBF velocities occurred only between cows with very severe fatty liver and those with severe, moderate, and mild fatty liver (Table 3). According to studies in humans (Abu-Yousef, 1992; Mohr et al., 1998) and cattle (Lomax and Baird, 1983), PBF depends predominantly on posture, physical activity, respiration, feed intake, and milk yield. Effects of physical activity, respiration, and posture as sources of variance were minimized in the present study by performing all Doppler examinations in the standing animal during peak inspiration. Effects of milk yield are reflected mostly by differences in feed intake be- tween high- and low-yielding dairy cows (Lomax and Baird, 1983). All of our cows had LDA; therefore, feed intake and milk yield were generally low at the time of examination (Table 1). Furthermore, no significant differences occurred between cows of the different TAG classes with respect to milk yield, DIM, age, or withers height; only mean BFT and BW differed significantly among TAG classes. Similar findings were reported previously and reflect the predisposition of cows with higher body condition for fatty liver (Bobe et al., 2004). The mean BFT of about $24 \mathrm{~mm}$ in cows with very severe fatty liver (Table 1) reflects a good, but not obese, body condition (Schröder and Staufenbiel, 2006). The degree of visceral fat accumulation was not assessed in cows of this study. However, BFT has a good correlation with total body fat (Schröder and Staufenbiel, 2006) and visceral fat (Wittek and Fürll, 2002). Thus, it appears unlikely that compression of intraabdominal blood vessels by excessive visceral fat stores was an important source of variance for the observed changes in portal blood flow in cows with very severe fatty liver in this study.

In humans, reduced PBF velocity because of fatty liver is explained by increased intrahepatic pressure and thus, increased vascular resistance and portal hypertension (Seifalian et al., 2001; Magalotti et al., 2004; McCuskey et al., 2004). In cattle, liver size and thickness can be estimated ultrasonographically (Braun, 2009; Haudum et al., 2011). Most of the correlations between PBF velocities and liver size and thicknessboth indicators of parenchymal swelling - were weak, but all were negative (Table 4), suggesting that the effect of fatty liver on hepatic hemodynamics is similar in cattle and humans. This is because an increase in hepatic volume caused by fatty infiltration is paralleled by an increase in intrahepatic pressure (Orrego et al., 1981).

In addition to the VPI and blood flow velocities in the portal vein, we also calculated the portal BFV. Analogous to findings in humans (Magalotti et al., 2004), we did not observe any significant differences in BFV among cows in different TAG classes (Table 3 ) or a significant correlation between portal BFV and the amount of fat in the liver (Table 2). We assume that the BFV is maintained by increased portal blood pressure, compensating for the increased vascular resistance. However, it is also possible that our measuring technique could not reflect the true BFV adequately, because we measured the flow velocities within the relatively large portal vein using the conventional PW technique. This technique tends to preferentially capture the centrally moving red blood cells because the sample volume of the PW Doppler is placed in the center of the vessel to avoid low-frequency clutter sig- 
Table 4. Pearson correlation coefficients ( $\mathrm{r}$ ) of ultrasonographic liver measurements and hepatic blood flow in the portal vein in 80 German Holstein cows

\begin{tabular}{lccccc}
\hline & \multicolumn{2}{c}{ Liver size } & & \multicolumn{2}{c}{ Liver thickness over portal vein } \\
\cline { 2 - 3 } \cline { 5 - 6 } $\begin{array}{l}\text { Doppler flow } \\
\text { characteristic }\end{array}$ & 10 th ICS $^{2}$ & 11 th ICS & & 10 th ICS & 11 th ICS \\
\hline $\mathrm{V}_{\max }$ & $-0.30^{*}$ & $-0.25^{*}$ & & $-0.35^{* *}$ & $-0.29^{*}$ \\
$\mathrm{~V}_{\min }$ & $-0.29^{*}$ & -0.22 & & $-0.29^{*}$ & -0.23 \\
$\mathrm{~V}_{\operatorname{mean}}$ & $-0.30^{*}$ & -0.24 & & $-0.33^{* *}$ & $-0.27^{*}$ \\
VPI & -0.09 & -0.15 & & $-0.27^{*}$ & -0.24 \\
BFV & -0.06 & -0.06 & & $-0.41^{* * *}$ & $-0.36^{* *}$ \\
\hline
\end{tabular}

${ }^{1} \mathrm{v}_{\max }=$ peak maximum blood flow velocity; $\mathrm{v}_{\min }=$ peak minimum blood flow velocity; $\mathrm{v}_{\text {mean }}=$ mean maximum blood flow velocity; $\mathrm{VPI}=$ venous pulsatility index; and $\mathrm{BFV}=$ blood flow volume.

${ }^{2} \mathrm{ICS}=$ intercostal space.

*** $P<0.001 ; * * P<0.01 ;{ }^{*} P<0.05$.

nals from the vessel wall. With a gradual decrease in flow velocity, the profile of velocity distribution across the diameter of the vessel changes (Freeman and Otto, 2005). It can be expected that with high-flow velocities, a thin peripheral margin of slowly flowing erythrocytes creates a so-called flat velocity distribution (resembling a cylinder), whereas with decreasing flow velocities, the profile becomes more peaked (resembling a cone). The reason for this is that the peripheral layer of slowly moving erythrocytes increases with decreasing flow velocity. For these reasons, in larger high-flow blood vessels with a cylindrical flow profile, conventional PW Doppler generates a better estimation of the mean flow velocity than in large vessels with a substantial decline in flow velocity (such as the portal vein). In the portal vein of a cow with severe fatty liver, PW measurements are based primarily on peak flow velocities occurring at the center of the vessel, rather than on the relatively broad peripheral layer of slowly moving blood cells. A novel pixel-wise flow volume measurement technique, which was recently described for use in humans (Scholbach and Scholbach, 2009), could be used to verify portal BFV in cows with advanced fatty liver.

\section{CONCLUSIONS}

Venous pulsatility index and blood flow velocity of the portal vein were inversely related to the grade of hepatosteatosis of dairy cows with LDA. The cause of these changes may be reduced vascular compliance in the liver because of fatty infiltration. These changes, which are believed to result from parenchymal swelling, became particularly pronounced when the hepatic TAG content exceeded $150 \mathrm{mg} / \mathrm{g}$ of $\mathrm{FW}$.

\section{REFERENCES}

Abu-Yousef, M. M. 1992. Normal and respiratory variations of the hepatic and portal venous duplex Doppler waveforms with simul- taneous electrocardiographic correlation. J. Ultrasound Med. 11:263-268.

Abu-Yousef, M. M., S. G. Milam, and R. M. Farner. 1990. Pulsatile portal vein flow: A sign of tricuspid regurgitation on duplex Doppler sonography. AJR Am. J. Roentgenol. 155:785-788.

Balci, A., S. Karazincir, H. Sumbas, Y. Oter, E. Egilmez, and T. Inandi. 2008. Effects of diffuse fatty infiltration of the liver on portal vein flow hemodynamics. J. Clin. Ultrasound 36:134-140.

Bobe, G., J. W. Young, and D. C. Beitz. 2004. Invited review: Pathology, etiology, prevention, and treatment of fatty liver in dairy cows. J. Dairy Sci. 87:3105-3124.

Bolondi, L., S. Gaiani, S. Li Bassi, G. Zironi, F. Bonino, M. Brunetto, and L. Barbara. 1991. Diagnosis of Budd-Chiari syndrome by pulsed Doppler ultrasound. Gastroenterology 100:1324-1331.

Braun, U. 1990. Ultrasonographic examination of the liver in cows. Am. J. Vet. Res. 51:1522-1526.

Braun, U. 2009. Ultrasonography of the liver in cattle. Vet. Clin. North Am. Food Anim. Pract. 25:591-609.

Braun, U., M. Flückiger, K. Feige, and A. Pospischil. 2002. Diagnosis by ultrasonography of congestion of the caudal vena cava secondary to thrombosis in 12 cows. Vet. Rec. 150:209-213.

Braun, U., N. Pusterla, and K. Wild. 1996. Ultrasonographic examination of the liver and gallbladder in cows: Abnormal findings. Compendium 18:1255-1269.

Dietrich, C. F., J. H. Lee, R. Gottschalk, G. Herrmann, C. Sarrazin, W. F. Caspary, and S. Zeuzem. 1998. Hepatic and portal vein flow pattern in correlation with intrahepatic fat deposition and liver histology in patients with chronic hepatitis C. AJR Am. J. Roentgenol. 171:437-443.

Dirksen, G. 1967. Present state of diagnosis, treatment and prophylaxis of left displacement of bovine abomasum. Dtsch. Tierarztl. Wochenschr. 74:625-633.

Doré, E., G. Fecteau, P. Helie, and D. Francoz. 2007. Liver abscesses in Holstein dairy cattle: 18 cases (1992-2003). J. Vet. Intern. Med. $21: 853-856$.

Drackley, J. K. 1999. ADSA Foundation Scholar Award: Biology of dairy cows during the transition period: The final frontier? J. Dairy Sci. 82:2259-2273.

Erdogmus, B., A. Tamer, R. Buyukkaya, B. Yazici, A. Buyukkaya, E. Korkut, A. Alcelik, and U. Korkmaz. 2008. Portal vein hemodynamics in patients with non-alcoholic fatty liver disease. Tohoku J. Exp. Med. 215:89-93.

Freeman, R. V., and C. M. Otto. 2005. Cardiac Hemodynamics. Pages 27-50 in Atlas of Echocardiography. M. A. Vannan, R. Lang, H. Rakowski, A. Jamil Tajik, ed. Current Medicine Group, Philadelphia, PA.

Gaál, T., and F. Husveth. 1983. Comparison of the liver biopsy sample and the "whole liver" in respect of lipid content and fatty acid composition of lipids. Acta Vet. Hung. 31:51-56.

Gallix, B. P., P. Taourel, M. Dauzat, J. M. Bruel, and M. Lafortune. 1997. Flow pulsatility in the portal venous system: A study of 
Doppler sonography in healthy adults. AJR Am. J. Roentgenol. 169:141-144.

Görg, C., J. Riera-Knorrenschild, and J. Dietrich. 2002. Pictorial review: Colour Doppler ultrasound flow patterns in the portal venous system. Br. J. Radiol. 75:919-929.

Greenway, C. V., and W. W. Lautt. 1988. Distensibility of hepatic venous resistance sites and consequences on portal pressure. Am. J. Physiol. 254:H452-458.

Gröhn, Y., and L. A. Lindberg. 1982. Methodological aspects of the microscopy of bovine liver biopsies. J. Comp. Pathol. 92:567-578.

Haudum, A., A. Starke, M. Beyerbach, P. Wohlsein, and J. Rehage. 2011. Ultrasonographic assessment of liver dimensions in dairy cows with different hepatic triacylglycerol content. J. Anim. Sci. doi:10.2527/jas.2010-3287.

Herdt, T. H. 1988. Fatty liver in dairy cows. Vet. Clin. North Am. Food Anim. Pract. 4:269-287.

Honnens, A., C. Voss, K. Herzog, H. Niemann, D. Rath, and H. Bollwein. 2008. Uterine blood flow during the first 3 weeks of pregnancy in dairy cows. Theriogenology 70:1048-1056.

Iwao, T. 1987. Ultrasonographic appearance of diffuse changes in the bovine liver. Jpn. J. Vet. Res. 35:130.

Johannsen, U., S. Menger, R. Staufenbiel, and H. Klukas. 1993. Untersuchungen zur Morphologie und funktion der Leber von Hochleistungskühen. 2. Wochen post partum. Dtsch. Tierarztl. Wochenschr. 100:177-181.

Jorritsma, R., H. Jorritsma, Y. H. Schukken, P. C. Bartlett, T. Wensing, and G. H. Wentink. 2001. Prevalence and indicators of post partum fatty infiltration of the liver in nine commercial dairy herds in the Netherlands. Livest. Prod. Sci. 68:53-60.

Jorritsma, R., H. Jorritsma, Y. H. Schukken, and G. H. Wentink. 2000. Relationships between fatty liver and fertility and some periparturient diseases in commercial Dutch dairy herds. Theriogenology 54:1065-1074.

Joseph, A. E., K. C. Dewbury, and P. G. McGuire. 1979. Ultrasound in the detection of chronic liver disease (the "bright liver"). Br. J. Radiol. 52:184-188.

Kremer, W. D., E. N. Noordhuizen-Stassen, F. J. Grommers, Y. H. Schukken, R. Heeringa, A. Brand, and C. Burvenich. 1993. Severity of experimental Escherichia coli mastitis in ketonemic and nonketonemic dairy cows. J. Dairy Sci. 76:3428-3436.

Lautt, W. W., C. V. Greenway, D. J. Legare, and H. Weisman. 1986. Localization of intrahepatic portal vascular resistance. Am. J. Physiol. 251:G375-G381.

Liebich, H. G. 1999. Leber. Pages 218-228 in Funktionelle Histologie der Haussäugetiere. Vol. 3. H. G. Liebich, ed. Schattauer Verlag, Stuttgart, Germany.

Lomax, M. A., and G. D. Baird. 1983. Blood flow and nutrient exchange across the liver and gut of the dairy cow. Effects of lactation and fasting. Br. J. Nutr. 49:481-496.

Magalotti, D., G. Marchesini, S. Ramilli, A. Berzigotti, G. Bianchi, and M. Zoli. 2004. Splanchnic haemodynamics in non-alcoholic fatty liver disease: Effect of a dietary/pharmacological treatment. A pilot study. Dig. Liver Dis. 36:406-411.

Maxie, M. G., ed. 2007. The liver and biliary system. Pages 310-316 in Jubb, Kennedy, and Palmer's Pathology of Domestic Animals. 5th ed. Vol. 2. Elsevier, Philadelphia, PA.

McCuskey, R. S., Y. Ito, G. R. Robertson, M. K. McCuskey, M. Perry, and G. C. Farrell. 2004. Hepatic microvascular dysfunction during evolution of dietary steatohepatitis in mice. Hepatology 40:386-393.

McGavin, M. D., and J. F. Zachary. 2007. Lipids. Pages 39-42 in Pathologic Basis of Veterinary Disease. 4th ed. M. D. McGavin and J. F. Zachary, ed. Elsevier, Philadelphia, PA.
Mohamed, T., H. Sato, T. Kurosawa, and S. Oikawa. 2004. Ultrasonographic localisation of thrombi in the caudal vena cava and hepatic veins in a heifer. Vet. J. 168:103-106.

Mohr, H. H., W. Godderz, and K. H. Meyer zum Buschenfelde. 1998. Die Duplexsonographie der Leber und des Pfortadersystems. Med. Klin. 93:669-677.

Morrow, D. A., D. Hillman, A. W. Dade, and Y. Kitchen. 1979. Clinical investigation of a dairy herd with the fat cow syndrome. J. Am. Vet. Med. Assoc. 174:161-167.

Orrego, H., L. M. Blendis, I. R. Crossley, A. Medline, A. Macdonald, S. Ritchie, and Y. Israel. 1981. Correlation of intrahepatic pressure with collagen in the Disse space and hepatomegaly in humans and in the rat. Gastroenterology 80:546-556.

Raoofi, A., T. T. Bazargani, and A. H. Tabatabayi. 2001. An abattoir survey on the frequency of fatty liver syndrome in dairy cows from the suburbs of Tehran. Trop. Anim. Health Prod. 33:15-19.

Reid, I. M., and R. A. Collins. 1980. The pathology of post-parturient fatty liver in high-yielding dairy cows. Invest. Cell Pathol. 3:237-249.

Reynolds, C. K., P. C. Aikman, B. Lupoli, D. J. Humphries, and D. E. Beever. 2003. Splanchnic metabolism of dairy cows during the transition from late gestation through early lactation. J. Dairy Sci. 86:1201-1217.

Reynolds, C. K., D. L. Harmon, and M. J. Cecava. 1994. Absorption and delivery of nutrients for milk protein synthesis by portaldrained viscera. J. Dairy Sci. 77:2787-2808.

Scheinfeld, M. H., A. Bilali, and M. Koenigsberg. 2009. Understanding the spectral Doppler waveform of the hepatic veins in health and disease. Radiographics 29:2081-2098.

Scholbach, T., and J. Scholbach. 2009. Dynamic sonographic tissue perfusion measurement. J. Med. Ultrasound 17:71-85.

Schröder, U. J., and R. Staufenbiel. 2006. Invited review: Methods to determine body fat reserves in the dairy cow with special regard to ultrasonographic measurement of backfat thickness. J. Dairy Sci. 89:1-14.

Seifalian, A. M., A. El-Desoky, and B. R. Davidson. 2001. Hepatic indocyanine green uptake and excretion in a rabbit model of steatosis. Eur. Surg. Res. 33:193-201.

Starke, A., A. Haudum, R. Busche, M. Beyerbach, S. Dänicke, and J. Rehage. 2010a. Technical note: Analysis of total lipid and triacylglycerol content in small liver biopsy samples in cattle. J. Anim. Sci. 88:2741-2750.

Starke, A., A. Haudum, G. Weijers, K. Herzog, P. Wohlsein, M. Beyerbach, C. L. de Korte, J. M. Thijssen, and J. Rehage. 2010b. Noninvasive detection of hepatic lipidosis in dairy cows with calibrated ultrasonographic image analysis. J. Dairy Sci. 93:2952-2965.

Stöber, M. 1990. Kennzeichen, Anamnese, Grundregeln der Untersuchungstechnik, allgemeine Untersuchung. Verlag Paul Parey, Berlin, Germany.

Sun, C. K., X. Y. Zhang, and A. M. Wheatley. 2003. Increased NAD(P) $\mathrm{H}$ fluorescence with decreased blood flow in the steatotic liver of the obese Zucker rat. Microvasc. Res. 66:15-21.

Teichgräber, U. K., M. Gebel, T. Benter, and M. P. Manns. 1997. Duplexsonographische Charakterisierung des Lebervenenflusses bei Gesunden. Ultraschall Med. 18:267-271.

Weijers, G., A. Starke, A. Haudum, J. M. Thijssen, J. Rehage, and C. L. De Korte. 2010. Interactive vs. automatic ultrasound image segmentation methods for staging hepatic lipidosis. Ultrason. Imaging 32:143-153.

Wittek, T., and M. Fürll. 2002. Untersuchungen zu Körperkondition und abdominalen Fettdepots in Beziehung zur Fettmobilisation bei an Labmagenverlagerung erkrankten Kühen. Tierarztl. Umsch. 57:302-309. 